\title{
Systems and Techniques for Removal of Failed Fixed Partial Dentures: A Review
}

\author{
Mohammed Mohammed Al Moaleem \\ Department of Prosthetics, College of Dentistry, Jazan University, Jazan, Kingdom of Saudi Arabia
}

Email address:

drmoaleem2014@gmail.com

\section{To cite this article:}

Mohammed Mohammed Al Moaleem. Systems and Techniques for Removal of Failed Fixed Partial Dentures: A Review. American Journal of Health Research. Vol. 4, No. 4, 2016, pp. 109-116. doi: 10.11648/j.ajhr.20160404.17

Received: June 8, 2016; Accepted: June 20, 2016; Published: July 18, 2016

\begin{abstract}
FPDs have a long life span but sometimes they should be removed for several reasons at which they are; secondary caries, the need for root canal treatment, severe gingival recession or periodontal disease, loosened retainer of a bridge, post loosening, root fracture, over contoured and unaesthetic restorations. The removal of temporary crowns and bridges are usually straightforward, while the removing of permanent cemented restorations are always an unpleasant, anxietyridden, risky subject for both dentist and patient. So the objective of the bridge removal is the ability to reuse them and to avoid damaging of the underlying tooth and supporting structures. The FPDs removal instruments are: large spoon excavator, scalar tip, brass ligature wires, matrix band, chisel and hammer. In addition to that, there are also coronal disassembly crown remover forceps, precision-made air-activated units; modified techniques have also been highlighted in this article for ease of use for the clinician. The aim of this review is to give an overview and describe the various available systems and techniques to remove the FPDs and to provide different options for each clinical condition. A PubMed literature was conducted up to June 2015 using the keywords: Crown and bridge (removal, disassembly, failure). Additionally, the bibliographies of 5 previous reviews, their cross references were manually searched.
\end{abstract}

Keywords: Crown Removal Systems, Bridge Failures, Removal Techniques

\section{Introduction}

Fixed partial dentures (FPDs) have limited life span in the dynamic oral environment. They may need to be removed due to functional, biological or aesthetic failures [1].

Removing the cemented prosthesis from the abutments may results to harm the periodontal tissues, abutment tooth structures or cores. It becomes more difficult with the using of adhesive resin cements [2]. FPDs can be removed due to multiple or secondary caries, the need for root canal treatment (RCT), porcelain fracture and gingival recession resulting from crown margin affecting the biologic width. Furthermore, it could be removed also due to periodontal disease, loss of retention or post, loosened retainer of a bridge, root fracture, over contoured and rough restorations [3-4]. Since the repair of these restorations with different materials and methods might fail [5-7], such FPDs need to be removed [1] [8].

There are a variety of instruments available for dentists to remove the failed FPDs, but many of them exert extracting forces to the tooth and supporting biological tissues. This may results in a lot of discomfort to the patient [2].

Taper of the preparation, restoration design and structure, cement used, and the removal systems are factors that can affect the removal of a cemented FPDs [9].

The FPDs may be fabricated from provisional prosthesis cemented to the abutment teeth with temporary cements. Their removal are usually simple by using hand instruments, a traumatically removed by breaking the weak cement layer between the restoration and tooth. The permanent FPDs restorations are fabricated from metal, metal-ceramic or ceramic only and cemented with permanent cements, their removal are more challenging due to resin or glass ionomer cements used [8].

Many techniques and systems have been mentioned in this literature for the safe removal of FPDs [1] [8] [10-15]. They may vary from instruments available in dental clinics such as a large spoon excavator, scalar tip, and brass ligature wires, chisel and hammer to specific coronal disassembly instruments such as crown remover forceps, impact delivering devices, also crown sectioning diamond or carbide burs and crown 
splitters [1]. Combinations of more than one technique are useful to remove some unusual cases. A clear understanding of action of each instrument or system is essential for a safe and effective removal [1]. The aim of this review is to give an overview and highlight the various systems or techniques available to remove the fixed partial dentures and to provide different options for each clinical condition.

\subsection{Literature Search Strategy and Data Collection}

To search the available literature we carried out a web-based search using the advanced features through. Google Scholar, PubMed and journal-specific websites were used to review literatures related to FPDs removal systems and techniques. The search of literatures were carried out up to 2015 using the keywords crown and bridges (removal techniques, coronal disassembly, systems) and laser de-crowning. The last literature for this review was published on JUNE 2015.

\subsection{Clinical Types of FPDs Failures}

The types of failures can be classified based on mode, into biological, mechanical, esthetic, functional, iatrogenic, and psychological [16-19].

BIOLOGICAL failures; due to pulp injury, over prepared tooth, inadequate pulp protection resulted in recurrent caries and infection. Moreover, abutment fracture, coronal or radicular discomfort, traumatic occlusion, pressure on soft tissue resulted in periodontal breakdown, and also inadequate number of abutments, poor oral hygiene, RCT or retreatment and metal allergies.

MECHANICAL failures; at which they could be due to non-fitting restoration caused by expansion of metal substructure, distortion of the margins, bubbles in occlusal or margin regions. Although, excessive oxide layer inside retainer, tight contact or prosthetic connector fracture.

ESTHETIC failures; they might be due to improper shade selection, over-contoured FPDs, improper shade selection, and failure to identify patient expectations.

CEMENTATION failures; at which they could be because of lack of ideal preparation features, improper cement selection, mixing technique, thicker space, inadequate isolation and incomplete removal of temporary cement are factors of failures.

\subsection{Causes and When to Remove FPDs}

FPDs can be removed during fabrication of the restoration e.g., after temporary cement of either provisional or permanent FPDs (Fig. -1, a), after formation of periodontal papillae contour (Fig. -1, b), during porcelain try-in with occlusal adjustment (Fig. -1, c) and after re-contouring of the pontic area (Fig. -1, d). Also removal of the FPDs can be after definitive cementation in the patient mouth, due to temporary failure in the bonding (Fig. -1, e), fracture of the prosthesis and replace it with repair (Fig. -1, f), improper laboratory construction (Fig. -1, g), esthetic failure (Fig. -1, h) and fracture of the connector (Fig. -1, i).

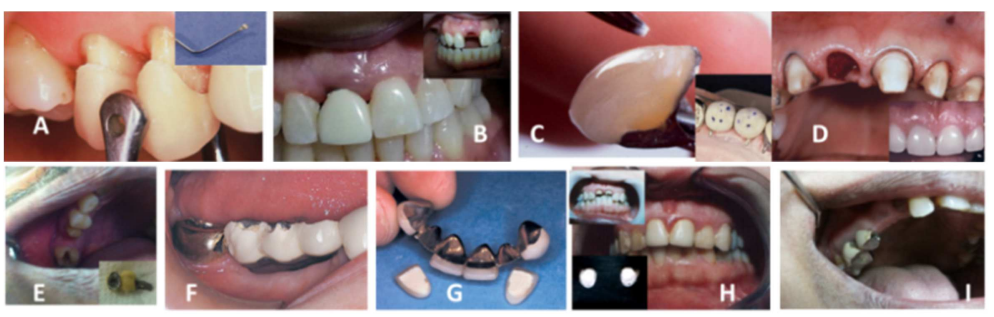

Figure 1. Different causes of FPDs removal.

\section{Classification of FPDs Removal Techniques and Systems}

There are different available systems and techniques to remove failed FPDs, but little information were published about the classification of available systems, which can help the clinician to choose the proper one depending upon the clinical situation. A combination of Janardanan, et al, Sharma et el, Ingle et al, Addy et al, Rosenstiel et al, Alsiyabi and Felton [1] [8-9] [19-21] with some modification resulted in a classification into four systems and techniques are shown as the following:.

\subsection{More Conservative}

The safest technique, works by breaking the luting cement and dislodge the restoration enabling it to be removed and can be re-cemented successfully.

\subsubsection{Ultrasonic}

It is a traumatic technique for FPDs removal by the use of special scalar tips (Piezon Ultrasonic, EMS, Fotips rest gate, Dallas, USA) (Fig. -2, a), which are placed in restoration margins. It is depending in the application of ultrasonic energy to remove the FPDs by breakdown the luting cement. Applying the vibration for a long time may results in ceramic crack, while the heat generated can cause damage to the pulp, so copious water spray is essential [22]. It could be used alone, or in combination with other techniques, and can be successful to disrupt the luting cement to remove intact restorations [1] [8]. Its disadvantage is time consuming. The effect of ultrasonic vibration on retention of restorations has been proved to be negative [23]. Melo Filho et al [24] concluded that the application of ultrasonic vibration at the gingival margin of the crown for $15 \mathrm{~s}$ may cause a reduction in tensile bond strength due to breakdown the cement layers [1] [8].

\subsubsection{Richwill FPDs Remover}

Almore International, Inc, Portland, Oregon is a thermoplastic adhesive resin that has been advocated for the removal of FPDs [25]. It is a water soluble resin tablet, which 
becomes pliable at $145^{\circ} \mathrm{F}$, then softened in warm water for $1-2$ minutes and placed in the incisal or occlusal surfaces of the prosthesis to be removed. The patient is instructed to occlude and compress on it till the resin block gets compressed to $2 / 3$ of its original size (Fig. -2, b1). Although, then it should be cooled with water from triple spray syringe until it become hard. The patient is instructed to sudden open mouth rapidly and forcefully. This action will remove the crown due to breakage of the cement seal (Fig. -2, b2). The success rate of this technique has been reported to be $100 \%$ for temporary crowns and $60 \%$ for the dislodgement of cast restorations in conjunction with the application of ultrasonic energy [26]. It is contraindicated in the non-secure restoration or filling, mobile teeth in the opposing arch. So, careful evaluation of the integrity of the opposing tooth or restoration is essential, otherwise it may cause removal of restoration or mobile tooth. The manufacturer recommends tying a length of dental floss to the tablet to prevent aspiration [1] [8] [24].

\subsubsection{Trial Crown Tractors and Remover}

They are likes and called grasping forceps (Hu-Friedy Co, Chicago), since it works by firm grip over the FPDs with the aid of rubber or soft grips and powder designed to dislodge the restoration without damaging the ceramic margins (Fig. 2, c). It works Also by applying inward pressure on two opposing handles. Some of them are provided with turn screws to prevent crushing of the crown. They are particularly effective for removing FPDs (provisional, have been cemented with temporary cement, or difficult to remove at the try-in stage). Another type is the Roydent Bridge Remover forceps (Roydent Dental Products, Rochester Hills, $\mathrm{MI}$ ), it has tips engage the margins of the crown, while the adjacent tooth is used as the fulcrum. The crown will be elevated off the tooth when the handles are squeezed together. That's may produce crack to the porcelains margins [1] [8].

\subsubsection{Lasers}

As Er, Cr: YSGG lasers $2780 \mathrm{~nm}$ to safety remove of all ceramic restorations in an expeditious fashion, and without fear of creating iatrogenic damage to underlying tooth structure. This will be a great promise for the dentist, patient, and dental laboratory technicians [30-31] which can result in time and cost saver for all of them. The use of all-ceramic restorations may require replacement due to caries, fracture, poor initial placement, problems that the patients notice with respect to position, shape, or shade (Fig. -2, d1) [28-29]. The laser wavelength cannot be absorbed by porcelain structures. Hence, they pass through porcelain and are absorbed in the water present in the luting agent as Erbium which will be absorbed in the. Application of Er, Cr: YSGG, $20 \mathrm{~Hz}$ for 1-2 min on each side will aid in the removal of the restoration (Fig. - 2, d2-d4). However, there is no doubt that the use of erbium lasers for veneer removal is an exciting alternative to any other technique [27]. Morford et al [30] have made use of Er-YAG laser at wavelength of $2940 \mathrm{~nm}$ and $133 \mathrm{~mJ}$ output with the fiber tip positioned 3-6 $\mathrm{mm}$ from the veneer surface for de-bonding all ceramic veneers within a period of 31-290 s. Oztoprak et al [31] have shown that Er-YAG laser with wavelength at $2940 \mathrm{~nm}$, applied for 3-9s with $2 \mathrm{~mm}$ distance on the labial surface in horizontal strokes caused a 9 fold reduction in bond strength of luting composite to enamel. Laser makes thermal softening of the resin without any effect on the enamel of the tooth [1] [27-28].

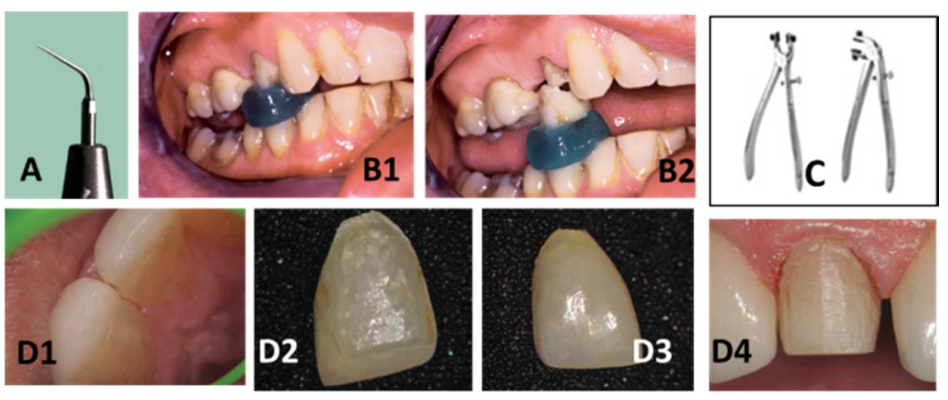

Figure 2. More conservative techniques and systems.

\subsection{Conservative Techniques}

These systems are working by applying a percussion or traction force to breakdown the sealed luting cement and enabling the FPDs to be removed. The prosthesis remains intact and can be reused. It may damage the cores and periodontally involved teeth [1] [8-9] [19].

\subsubsection{Chisel and Sliding Hammer Remover}

In which, a suitable tip is selected to engage the crown margin and then a weight is slid along the shaft in a series of short, quick taps to loosen the restoration. Various designs are available in market (Fig. -3, a). They are uncomfortable for the patients and no more used these days. It is not recommended to be used for periodontally involved teeth and may damage the porcelain margins [19].

\subsubsection{Manual Back Action Remover}

It is similar to Pulpdent FPDs Remover (Pulpdent Corporation, Watertown, USA), which engage the margins by a tip, which is attached to a shaft. The shaft has a sliding weight and impact force is applied by activation of the weight manually (Fig. -3, b). Activation of the load may cause the rod to shift away easily from the long axis of the crown to be removed. It could be a little bit traumatic to the patient, also may causing a discomfort and luxation of the ligament. It is mainly indicated for the removal of temporarily cemented FPDs [1] [19] [32]. 


\subsubsection{Spring Loaded Back Action Remover}

They are back action such as hammer Dental Type $\mathrm{C}$ crown remover (Kentzler Kaschner Dental GmbH, Ellwangen, Germany), that are spring loaded, which compressed manually and released to deliver the impact force (Fig. -3, c) [1] [8].

\subsubsection{Spring Loaded Semi-automatic Remover}

Such as Crown-A-Matic (Peerless International, Inc. S. Easton, MA) which can be operated easily with one hand while the other can be used to secure the device at the FPDs margin. Hence, they have better directional control when tapping forces are applied. The spring is compressed by sliding the outer tube over the inner tube. Pressing the button provides back action to remove the prosthesis (Fig. -3, d). These devices should be removed and reactivated each time it operated [1] [8] [19].

\subsubsection{Spring Loaded Automatic Remover}

Such as (Dexell automatic crown remover, Kentzler Kaschner Dental Type B, Medesy Crown clix) which can be used in a single handed manner, and they need not be removed for reactivation. By pressing the handle, the shock impulses are released successively (Fig. -3, e). It can be attached with loops, which are passed through the connector area to deliver impulses for removal of FPDs [1] [8].

\subsubsection{Pneumatic CORONA Flex FPDs Remover}

It is a modification of sliding hammer using brass wire threaded through bridge embrasures to form a loop on to which a force can be applied to dislodge the FPDs without its risks [13]. It is an air-driven device makes use of compressed air and connects to dental hand-piece hoses in dental units via KaVo MULTIflex coupler to break the cement seal. The main component is a gun like a barrel with a small extension at the end of rotating at $360^{\circ}$, which delivers the impact force (Fig. $3, \mathrm{f1}$ ). Also includes loops to thread under FDP connectors that attach to the holder, calipers, and an adhesive clamp that can be attached to individual crowns with auto polymerizing resins. The force is then applied via the adhesive clamp to dislodge the crown [1]. It has different designed tips. The device works well on FDPs removal by loop holder and loops (Fig. -3, f2) or clamps (Fig. -3, f3). It is well tolerated by patients [20]. The loop is threaded under the connector and the tip of the FPDs remover is placed on the bar. A controlled low impact, short amplitude shocks at its tip along the long axis of the abutment tooth and the index finger from the air valve on the hand piece [1]. The Easy Pneumatic FPDs Remover II (Dent Corp, White Plains, NY) are same class of this type (Fig. -3, f4). Similar techniques were demonstrated by Garver and Wisser [33] and Liebenberg [34] where auto polymerizing resin was applied onto the ceramic veneer to serve as undercuts for application of the tip of the forceps [1] [8] [19].

\subsubsection{ATD Automatic FPDs Remover}

Like (J. Morita, Irvine, CA) which can be attached to the dental unit (Fig. -3, g1). It can be used for removal all types of FPDs, single crown (Fig. -3, g2), multi unites FPDs (Fig. 3, g3, g4) resin bonded bridge (Fig. -3, g5). Oruç [36] demonstrated removal FPDs using of a ligature wires passing through the embrasures of the bridge and connected to a cone, which is attached to a horizontal bar on which the impact can be delivered. For removal of loosened retainer of FPD, it requires time for fabrication, and considerably reduction on chair side time. Verrett and Mansueto [37] made use of a two piece matrix on the buccal and lingual surface of the bridge, connected to each other by means of a nut and bolt. Application of tapping force through resin matrix may cause safe removal of the FPD [35].

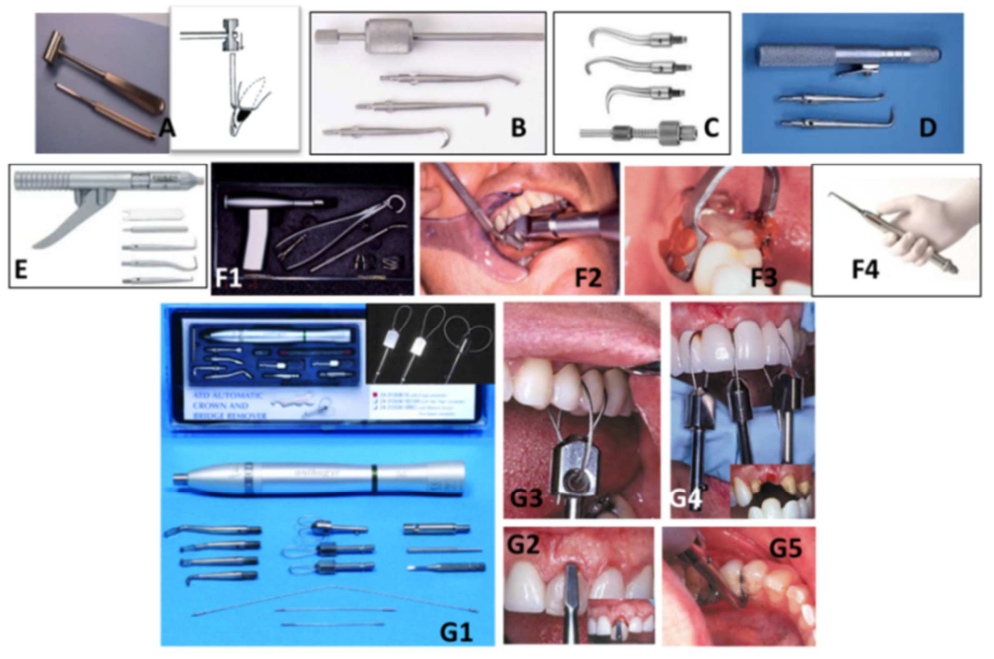

Figure 3. Conservative techniques and systems.

\subsection{Semi Conservative Techniques}

These techniques are actively engage the FPDs by means of a small access hole cut through the restorations, in order to support the abutment while the lifting force is applied on the prosthesis. Their advantages are time saver, more comfortable to the patient; allow safe separation from each other, and less traumatic application of force to dislodge the FPDs. Also they have the ability to be reused as provisional 
FPDs. The hole can be filled and repaired with composite or compommer filling materials [19] [38]. While the respective substructure can be reused during the fabrication of the new FPDs [1] [8] [21] [39].

\subsubsection{The Mtalift System}

Classic Practice Resources, Baton Rouge, LA and based on the "jack-screw" principle in which a precision hole is drilled with a diamond bur through the occlusal surface of a FPDs (Fig. -4, a1), the area around the periphery of the hole is undermined before a threaded screw is wound into the space (Fig. -4, a2) [19] [26]. A thread is cut in the metal of the FPDs and, when the instrument is stopped from advancing by contact with the underlying core (Fig. -4, a3). the continued rotation of the screw results in a jacking force that displaces the crown from the abutment (Fig. -4, a4), turning of the instrument against the dentin past the metal causes the cement seal to break [1] [8]. The removed ceramic should be sufficient from the area where the hole is drilled to minimize the risk of cracks.

\subsubsection{The Kline System}

(Brasseler, Savannah, GA) is similar to Mtalift, it is a stainless steel plier like instrument (Fig. $-4, \mathrm{~b}$ ) with one end having a pin (engages a hole created on the cusp tip) $6 \mathrm{~mm}$ long and $1.6 \mathrm{~mm}$ diameter, while the other end being flat and pointed tip (engages the margin of FPDs). Squeezing the handle produces pressure causing the cement layer to break [1] [8].

\subsubsection{The Wamkey System}

(Dentsply, Ballaigues, Switzerland), is a simple narrowshanked cam devices available in three sizes (Fig. -4, c1) makes the use of oval shaped keys of dimensions ranging from 2.5 to $5 \mathrm{~mm}^{2}$ on any surface of the crown (Fig. -4, c2) [32]. It is inserted into the tunnel created between the occlusal of the preparation and the fitting surface of the FPDs, with the broadest surface of the cam parallel to the occlusal surface, until it is centrally placed when it is rotated about the axis of the shank through 90 degree [1] [8]. The force applied should be in the path of insertion of the FPDs which is easily dislodged (Fig. -4, c3). In this approach the cement layer should be identify before extending the channel across the occlusal surface.

\subsubsection{The Higa System}

(Higa Mfg Ltd., West Vancouver, B. C. Canada), in which a wire is threaded under the soldered joint connecting the crown to the pontic and pulled into a parallel loop (Fig. -4, d1). This make the use of a cable system that pulls up the FPDs, while a support peg holds down the prepared tooth (Fig. -4, d2). The support pin is inserted into the hole on the occlusal surface (Fig. -4, d3), tightening of the cable causes equal pressure to be applied to the FPDs in the upward direction causing it to lift up while the pin supports the abutment (Fig. -4, d4) [1].

\subsubsection{Bucco-Lingual 'Dimple' Technique}

[1] [39], it can be utilized in certain clinical conditions to minimize the noxious intraoral grinding of porcelain and metal for removing cemented FPDs. In this technique [39] dimples are created on the buccal and lingual surfaces of the FPDs with a small round bur in the gingival 1/3 (will prevent the slipping of pliers from the smooth hard surfaces of porcelain or metal) (Fig. -4 , e1) to act as a receptacles for Baade Pliers (Buffalo Dental, Syosset, NY). It is available in both straight and contra-angled variations for adaptability to different intraoral applications. The twisting motion of the hands and wrist helps to remove the crown by breaking the sealing cement. After making the dimples and the Baade pliers are in position (Fig. -4. e2), the operator attempts to break the cement seal and remove the FPD with a twisting motion of the hand and wrist. In cases where the dimple technique alone is successful, the delighted practitioner has removed the crown quickly and intact without any intraoral grinding, prying, or tapping (Fig. -4, e3). It works well on over tapered prepared teeth and short clinical abutments, and contraindicated in periodontally compromised dentition, unfavorable crown-to-root ratio, or excessive mobile teeth [39]. GC pliers (GC America, Alsip, IL), is a similar device for removing temporarily cemented, or retentive FPDs during try-in. It has replaceable rubber tips at the beak ends which grab the restoration and will not scratch highly finished surfaces (Fig. -4, e4). An emery powder is applied to the rubber tips to provide additional friction and avoiding scratch glazed porcelain or polished metal surfaces [39].

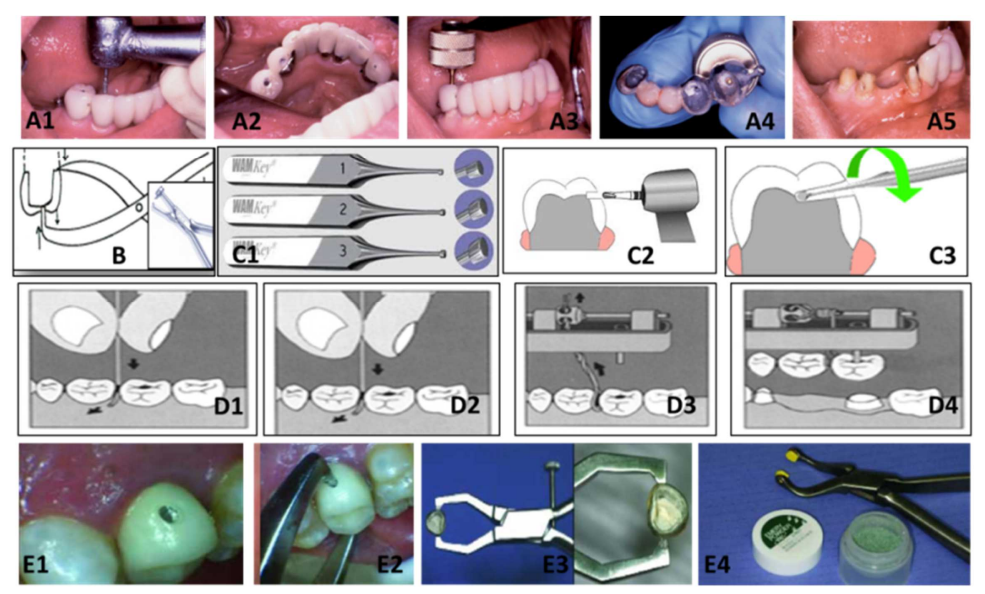

Figure 4. Semi-conservative techniques and systems. 


\subsection{Destructive Technique (Crown Splitters and Spreaders)}

In this technique the FPDs or crowns are usually sectioned with diamond bur [1] [8-9] [19], resulted in non-reusable or damaged prosthesis. It is the most common for all dentists [8] [20]. It is indicated in the presence of underlying mobile or RCT teeth, teeth cemented with resin cement, esthetic and periodontal failures [1] [20], resulted in the removal of failed FPDs with saving the abutment tooth structures. The crosscut tungsten carbide burs are usually used for sectioning of base metal, whereas course diamond burs are useful for high noble alloys [40]. A lot of course carbide burs as well as special Talon burs (metal and crown cutter) have blades at the top and sides, allowing them to cut vertically as well as horizontally (Fig. -5, a). The crowns are splinted from both buccal, lingual sides passing through the incisal edge (Fig. -5, b). The Brasseler Crown Removal System (Brasseler, Savannah, GA) can be used after sectioning, in which placed in the cut area and gently rotated to force the halves of the crown apart (Fig. -
5, c). Once the crowns are split open they need spreader to release the metal substructure from the tooth. Crown spreaders are inserted into the groove and rotated to break the cement seal. The application of such a crown splitter and spreads the split evenly, reducing the stress on the tooth/core. A Goldstein crown remover keys (Hu-Friedy Co, Chicago) are available as straight, $45^{\circ}$ angled and $90^{\circ}$ angled tips (Fig. -5 , d) making it possible to be used anywhere in the mouth. The Nordent, Osung RECDA and Medesy crown spreaders (Fig. ure,-5, e) are single ended with notched tips ("+" shaped) with more efficiency than flat ended types. The widening plier's type or crown remover of spreaders engages a slot created on the surface of the crown [1]. Gently squeezing the handle allows the beaks to separate and split the crown (Fig. -5 , f). For removal of multiunit joined crowns we need to section each crown alone (Fig. - 5, g), then extend the sectioning through the connectors of each crown, resulted in small pieces removable FPDs as shown in (Fig. -5, h).

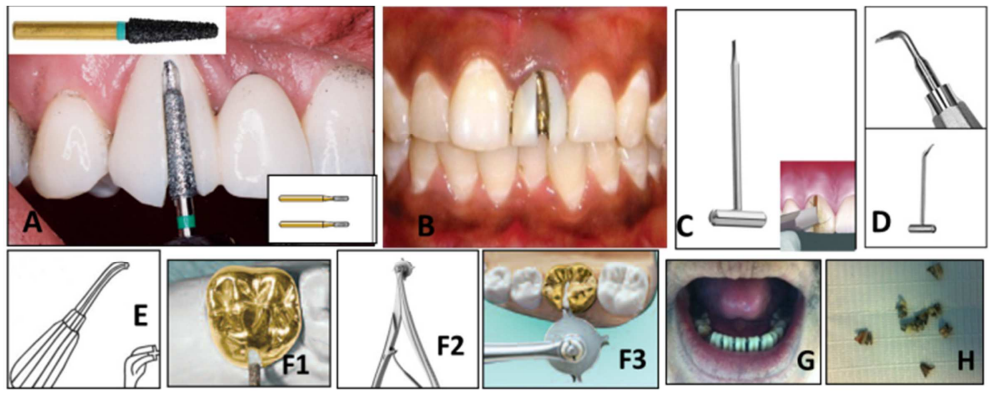

Figure 5. Destructive techniques and systems.

Table 1. Summary of techniques and systems for FPDs removal [1] [8-9] [19-20].

\begin{tabular}{|c|c|c|}
\hline System type & Advantages & Disadvantages \\
\hline Ultrasonic & A traumatic removal of crown, useful with other systems & $\begin{array}{l}\text { Long time application can cause ceramic cracks and pulp } \\
\text { injury. Furthermore, it is time consuming and may require } \\
\text { repair of restoration }\end{array}$ \\
\hline $\begin{array}{l}\text { Richwill adhesive } \\
\text { resin }\end{array}$ & $\begin{array}{l}\text { Less traumatic to the patient, easy to use, permits reuse of the } \\
\text { prosthesis }\end{array}$ & $\begin{array}{l}\text { Not indicated when there is a non-secure restoration or } \\
\text { prosthesis, mobile or periodontally compromised tooth in } \\
\text { the opposite arch, Not effective for permanent cementation }\end{array}$ \\
\hline Crown tractors & Use of rubber inserts allows safe removal of crown & $\begin{array}{l}\text { Not used in case of permanent cementations. Although, it } \\
\text { may cause cracks on porcelain margins }\end{array}$ \\
\hline Laser radiation & A traumatic technique, and does not damage the restoration, & $\begin{array}{l}\text { Dangerous when laser beam not directed properly, indicate } \\
\text { for all ceramic restorations }\end{array}$ \\
\hline Manual back action & Simple design, not expensive & $\begin{array}{l}\text { Impact activation causes the rod to shift away easily, the } \\
\text { intended axis of removal may harming the patient and } \\
\text { ligament }\end{array}$ \\
\hline $\begin{array}{l}\text { Spring loaded back } \\
\text { action }\end{array}$ & Easier to deliver impact forces compared to manual back action & Can cause trauma and luxation of the ligament \\
\hline $\begin{array}{l}\text { Spring loaded } \\
\text { semiautomatic }\end{array}$ & $\begin{array}{l}\text { Can be operated with one hand and the other hand can be used to, } \\
\text { secure device at FPDs margin, better directional control }\end{array}$ & Should be removed and reactivated after each operation \\
\hline $\begin{array}{l}\text { Spring loaded } \\
\text { automatic }\end{array}$ & $\begin{array}{l}\text { Can be used in a single handed manner. Not removed for } \\
\text { reactivation }\end{array}$ & Difficult to control the direction and amount of force \\
\hline $\begin{array}{l}\text { Pneumatic and ATD } \\
\text { automatic }\end{array}$ & Automatic reactivation, ease to use for all FPDs types & $\begin{array}{l}\text { Difficult to ascertain the path of withdrawal, time } \\
\text { consuming, costly }\end{array}$ \\
\hline $\begin{array}{l}\text { The Mtalift, Kline, } \\
\text { Wamky Systems }\end{array}$ & $\begin{array}{l}\text { Applies a downward force on the tooth while the crown or } \\
\text { restoration is removed, thereby preventing its fracture or extrusion, } \\
\text { Less trauma to tooth and surrounding structure, time saving }\end{array}$ & $\begin{array}{l}\text { Repairing the FPDs with esthetic restorative materials, } \\
\text { costly, need lot of equipment's }\end{array}$ \\
\hline $\begin{array}{l}\text { Bucco - Lingual } \\
\text { 'dimple' technique }\end{array}$ & $\begin{array}{l}\text { Minimum intraoral grinding, impact force can be directed in a } \\
\text { proper way with pliers by twisting motion of hand and wrist }\end{array}$ & $\begin{array}{l}\text { Not indicated in periodontally compromised teeth, } \\
\text { unfavorable crown/root ratio, excessive mobile teeth }\end{array}$ \\
\hline $\begin{array}{l}\text { Crown splitters and } \\
\text { spreaders }\end{array}$ & $\begin{array}{l}\text { Permits removal of FPD without damage to tooth and periodontal } \\
\text { tissues }\end{array}$ & $\begin{array}{l}\text { Permanent damage of FPDs, not reuse, more time, } \\
\text { expensive and unpleasant for patient }\end{array}$ \\
\hline
\end{tabular}




\section{Conclusions}

When removing cemented FPDs prostheses, many factors must be taken into considerations; type of cement used, condition of the underlying abutments and associated tissues, the condition of the prosthesis during and after their removal. The removal of temporary FPDs is usually simple, while the removal of permanent one has always been unpleasant, anxious, risky task for dentist and patient. Its removal should be prevented to avoid harming the underlying tooth or/ supporting structures and allow to reuse the prosthesis. The advantages and disadvantages of all available systems and techniques used for FPDs removal are listed in table - 1. It is difficult to suggest a universal system for FPDs removal. Selection of an ideal system depends on the clinical condition. Ultrasound, Richwill adhesive resin and crowns tractors are the instruments of choices in removal of temporary cemented restoration, resulted in breaking the luting cement and enabling it to be re-cemented. Manual back, spring loaded back, automatic loads systems may cause fracture of the cores and extraction of periodontally involved teeth. So we have to use these systems with sound underlying tooth structure, favorable path of removal and conventional cement used. In case of apprehensive patients, the pneumatic system that works by breaking down the cement seal through vibrations rather than the typical jack hammer effect can be suggested. The Mtalift, Kline and Wamky Systems are the choices for unfavorable path of insertion, resin cemented FPD prosthesis. Destructive techniques are indicated for periodontally involved and grossly decayed teeth to prevent damage to the abutment and supporting tissue, irrespective of the used luting cement. The modified techniques have also been discussed in this article for multi unites joined crowns.

\section{References}

[1] Janardanan K, Varkey V K, Lovely M, Anuroopa A. Coronal disassembly systems and techniques: An overview. J Interdisciplinary Dent 2014; 4: 33-40

[2] Gupta A. A Simple Chair side Technique of Removing Crown and Fixed Partial Denture Restorations. JDMT 2015; 4: 8-12.

[3] Goodacre CJ, Bernal G, Rungcharassaeng K, Kan JY. Clinical complications in fixed Prosthodontics. J Prosthet Dent 2003; 90: 31-41.

[4] Sorensen JA. A rationale for comparison of plaque-retaining properties of crown systems. J Prosthet Dent 1989; 62: 264-9.

[5] Gregory WA, Hagen CA, Powers JM. Composite resin repair of porcelain using different bonding materials. Oper Dent 1988; 13: 114-8.

[6] Al Moaleem MM: Evaluation of the Bonding Strength of the Intra-Oral Porcelain Repairing System with Different Surface Treatments. (2011), ISBIN: 978-3-639-32764-9. pp 53-7.
[7] Al Moaleem MM, Al-Qahtani NM. A combination of intra and extra oral technique for repairing a multi-unit metal ceramic fixed partial denture. Int J Dent Clinics 2012; 4: 84-86.

[8] Sharma A, Rahul GR, Poduval ST, Karunakar S. Removal of failed crown and bridge. J Clin Exp Dent 2012; 4: e167-72.

[9] Ingle JI, Bakland LK, Baumgartner JC. Ingle's Endodontics. 6th ed. Hamilton, Ontario: BC Decker Inc.; 2008. pp 1095-7.

[10] Williams FB, Portera JJ, Stephens AP. Removing a cemented metal-ceramic fixed prosthesis without damage: a custommade appliance. J Prosthet Dent 1984; 51: 656-9.

[11] Pruitt CO. A review of methods and instrumentation for removing crowns and bridges from prepared teeth. Gen Dent 1994; 42: 320-6.

[12] Sutherland JK, Cheeseman SL. Multiple prosthodontic uses for permanent crown remover forceps. J Prosthet Dent 1997; 77: 99-101.

[13] Williamson RT, Breeding LC. Removing a cemented fixed prosthesis using a crown remover. J Prosthet Dent 1993; 69: 634-5.

[14] Parreira FR, O'Connor RP, Hutter JW. Cast prosthesis removal using ultrasonics and a thermoplastic resin adhesive. J Endodo 1994; 20: 141-3.

[15] Loney RW. Practical uses for provisional crown remover forceps in fixed and removable prosthodontics. J Prosthet Dent 1992; 67: 734-6.

[16] Walton J. Gardner F, Agar J. A survey of crown and fixed partial denture failures: length of service and reasons for replacement. J Prosthet Dent 1986; 56: 416-21.

[17] Reuter J, Brose MO. Failures in full crown retained dental bridges. Br Dent J 1984; 157: 61-3.

[18] Wise MD. Failure in restored dentition-management and treatment, $2^{\text {nd }}$ Ed, Quintessence Publishing co 1996. Pp: 207235 .

[19] Addy LD, Bartley A, Hayes SJ. Crown and bridge disassembly, when, why and how. Dent Update 2007; 34: 140-50

[20] Rosenstiel SF, Land MF, Fujimoto J. Contemporary Fixed Prosthodontics, $4^{\text {th }}$ Ed. St. Louis (MO): Mosby Elsevier 2006: pp. 935-41.

[21] Alsiyabi AS1, Felton DA. Technique for removing cement between a fixed prosthesis and its substructure. J Prosthodont 2009; 18: 279-82.

[22] Abbott PV. Incidence of root fractures and methods used for post removal. Int Endod J 2002; 35: 63-7.

[23] McQuade MJ, Huget EF, de Simon LB, Levin MP. Effect of ultrasonic instrumentation on the retention of simulated cast crowns. J Prosthet Dent 1978; 39: 640-2.

[24] Melo Filho AB, Mori M, Jardini MA, Landim KT, Solis AC. Effect of ultrasonic instrumentation on the bond strength of crowns cemented with zinc phosphate cement to natural teeth. An in vitro study. Braz Oral Res 2008; 22: 270-4. 
[25] Oliva RA. Clinical evaluation of a new crown and fixed partial denture remover. J Prosthet Dent 1980; 44: 267-9.

[26] Westerman RD. A new paradigm for the construction and service of fixed prosthodontics. Dent Today 1999; 18: 62-9.

[27] Glenn A. van As. Using the Erbium Laser to Remove Porcelain Veneers in 60 Seconds Minimally Invasive, Efficient, and Safe, J Cosm Dent 2013; 28: 21-34

[28] van As Glenn. Laser Removal of Porcelain Veneers. Dent Today 2012; 16: 34-44.

[29] Morford CK, Buu NC, Rechmann BM, Finzen FC, Sharma $\mathrm{AB}$, Rechmann P. Er: YAG laser debonding of porcelain veneers. Lasers Surg Med 2011; 43: 965-74.

[30] Oztoprak MO, Tozlu M, Iseri U, Ulkur F, Arun T. Effects of different application durations of scanning laser method on debonding strength of laminate veneers. Lasers Med Sci 2012; 27: 713-6.

[31] Berk N, Berk G. The new era for porcelain veneers-remove them with your LASERS! Laser Congress. 4th Congress of the International Society for Oral Laser Applications SOLA, Bruges, Belgium, Oud St. Jan; 2007.

[32] Girard JL. Advancement in the removal of permanently cemented crowns and bridges. Smile Dent J 2010; 5: 30-6.
[33] Garver DG, Wisser RC. A safe crown-removal technique. J Prosthet Dent 1978; 39: 56-8.

[34] Liebenberg WH. Modification to a 'safe crown-removal technique’: A case report. Br Dent J 1994; 176: 71-3.

[35] Shuman IE. Removing of fixed prostheses using ATD automatic crown and bridge remover. Dental Products Report 2002; 36: 80

[36] Oruç S. Handmade fixed partial prosthesis remover. J Prosthet Dent 2002; 88: 232-3.

[37] Verrett RG, Mansueto MA. Removal of a metal-ceramic fixed partial denture with a loose retainer. J Prosthodont 2003; 12: 13-6.

[38] AL-Moaleem M M, Shah FK, Nausheen Saied Khan NS, Amit Porwal. The effect of thermocycling on the bonding of different restorative materials to access opening through porcelain fused to metal restorations. J Adv Prosthodont 2011; 3: $186-9$

[39] Herman GL. Bucco-lingual 'dimple' technique for removing full-crown and cast-metal restorations. J Mich Dent Assoc 2011; 93: 42-4.

[40] Siegel SC, von Fraunhofer JA. Comparison of sectioning rates among carbide and diamond burs using three casting alloys. J Prosthodont 1999; 8: 240-4. 